Article

\title{
Vitamin D Deficiency Is a Potential Risk for Blood Pressure Elevation and the Development of Hypertension
}

\author{
Yusuf Karadeniz ${ }^{1}$, Fatma Özpamuk-Karadeniz ${ }^{2, *(D)}$, Süleyman Ahbab ${ }^{3}$ D, Esra Ataoğlu ${ }^{3}$ (D) and Günay Can ${ }^{4}$ \\ 1 Division of Endocrinology and Metabolism, Department of Internal Medicine, Faculty of Medicine, \\ Necmettin Erbakan University, Konya 42010, Turkey; dryusufkaradeniz@gmail.com \\ 2 Department of Cardiology, Private Büyükşehir Hospital, Konya 42060, Turkey \\ 3 Department of Internal Medicine, University of Health Sciences, Haseki Training and Research Hospital, \\ Istanbul 34270, Turkey; drsahbab@gmail.com (S.A.); eataoglu@gmail.com (E.A.) \\ 4 Departments of Public Health, Cerrahpaşa Medical Faculty, Istanbul University, Istanbul 34098, Turkey; \\ gunaycan09@yahoo.fr \\ * Correspondence: kdrfatmakaradeniz@gmail.com; Tel.: +90-0507-233-4020
}

\section{check for}

updates

Citation: Karadeniz, Y.;

Özpamuk-Karadeniz, F.; Ahbab, S.;

Ataoğlu, E.; Can, G. Vitamin D

Deficiency Is a Potential Risk for

Blood Pressure Elevation and the

Development of Hypertension.

Medicina 2021, 57, 1297.

https://doi.org/10.3390/

medicina57121297

Academic Editors: Andrzej Slominski and Manfredi Rizzo

Received: 26 October 2021

Accepted: 19 November 2021

Published: 25 November 2021

Publisher's Note: MDPI stays neutral with regard to jurisdictional claims in published maps and institutional affiliations.

Copyright: (c) 2021 by the authors. Licensee MDPI, Basel, Switzerland. This article is an open access article distributed under the terms and conditions of the Creative Commons Attribution (CC BY) license (https:// creativecommons.org/licenses/by/ $4.0 /)$.
Abstract: Background and objectives: Hypertension is a global health problem and a major risk factor for cardiovascular diseases. Vitamin D deficiency is closely related to high blood pressure and the development of hypertension. This study investigated the relationship between the vitamin D and blood pressure status in healthy adults, and their 8-year follow-up was added. Materials and Methods: A total of 491 healthy middle-aged participants without any chronic illness, ages 21 to 67 at baseline, were divided into two groups as non-optimal blood pressure (NOBP) and optimal blood pressure (OBP). NOBP group was divided into two subgroups: normal (NBP) and high normal blood pressure (HNBP). Serum 25-hydroxy vitamin D levels were measured with the immunoassay method. 8-year follow-up of the participants was added. Results: The average vitamin D level was detected $32.53 \pm 31.50 \mathrm{nmol} / \mathrm{L}$ in the OBP group and $24.41 \pm 14.40 \mathrm{nmol} / \mathrm{L}$ in the NOBP group, and a statistically significant difference was found $(p<0.001)$. In the subgroup analysis, the mean vitamin D level was detected as $24.69 \pm 13.74$ and $24.28 \pm 14.74 \mathrm{nmol} / \mathrm{L}$ in NBP and HNBP, respectively. Together with parathyroid hormone, other metabolic parameters were found to be significantly higher in the NOBP. During a median follow-up of 8 years, higher hypertension development rates were seen in NOBP group $(p<0.001)$. Conclusions: The low levels of vitamin D were significantly associated with NBP and HNBP. The low levels of vitamin D were also associated with the development of hypertension in an 8-year follow-up.

Keywords: vitamin D; blood pressure; hypertension; parathyroid hormone

\section{Introduction}

Vitamin D deficiency is a very common health problem worldwide, and studies have shown that vitamin D deficiency is common in the Turkish population [1-3]. In addition to the well-known function of calcium and bone metabolism, vitamin D deficiency is related to many chronic diseases, such as metabolic syndrome, hypertension, diabetes mellitus, coronary artery disease, and heart failure [4]. Besides cardiovascular diseases, it has a role in inflammatory, autoimmune, neurodynamic diseases, and cancer etiology [5]. Except from systemic diseases, it has been shown that decreased vitamin D and increased cytokine levels in saliva are associated with local diseases, such as periodontal disease [6].

Hypertension is the main preventable cause of premature death and disability in the world [7]. Hypertension has many etiological factors, which include age, race, family history, obesity, sedentary lifestyle, using tobacco, high salt intake, stress, and consuming alcohol in a larger quantity. It is thought that vitamin D deficiency is one of these etiological reasons, and vitamin D level is inversely related to blood pressure (BP) and incident hypertension. However, the blood pressure-lowering effect of vitamin D replacement was 
not observed in most studies; it was found to be effective in a few studies [8]. Various studies revealing the mechanism between vitamin $\mathrm{D}$ and hypertension have been presented, and studies are continuing on this subject [9].

Pre-hypertension is the pre-clinic stage of hypertension and is an important risk factor for both the development of hypertension and cardiovascular diseases [10]. According to the latest ESC guideline, pre-hypertension was defined as normal and high normal instead [11]. The onset of hypertension can be delayed or prevented with adequate primary prevention. Most of the studies examined the association between vitamin D and BP but did not focus on pre-hypertension or the development of hypertension in the pre-hypertensive, low vitamin level group on long-term follow-up. To the best of our knowledge, no study has been conducted on the relationship between vitamin D pre-hypertension association and future hypertension development risk in the Turkish population. This study aimed to investigate the association between vitamin D status and pre-hypertension in healthy, disease-free adults. In addition, the 8-year follow-up of these patients was added, and the rate of hypertension and other chronic events were investigated.

\section{Materials and Methods}

\subsection{Participants}

This study consisted of 155 males and 336 females, a total of 491 individuals who were admitted to our hospital's outpatient clinic between December 2012 and July 2013 for routine health controls. The patients were followed for 8 years after admission. Physical examination findings and anthropometric measurements were noted. Biochemical parameters and plasma 25-hydroxy vitamin $\mathrm{D}(25-\mathrm{OH}$ vitamin $\mathrm{D})$ levels were analyzed. Participants were divided into two groups, normal to high normal blood pressure (NBPHNBP) and optimal blood pressure (OBP), according to 2018 ESC/ESH Clinical Practice Guidelines for hypertension [11]. We included NBP and HNBP in the non-optimal blood pressure group (NOBP). There were 289 people with NOBP, 101 men and 188 women, and 202 people with OBP, 54 of whom were male, and 148 were female. Patients diagnosed and treated before with a chronic disease, such as diabetes mellitus, hypertension, coronary artery disease, chronic renal, and liver disease; with an active infection; smokers; and who had received vitamin $D$ treatment in the last 6 months were excluded. Data from the 8-year follow-up period were obtained from medical records. This study was approved by the hospital's ethics committee. Informed consent was obtained from all participants.

\subsection{Measurements}

BP was measured twice with an aneroid sphygmomanometer from the right arm of all participants in a sitting position after $5 \mathrm{~min}$ of rest. BP values were reported in millimeters of mercury (mmHg). Hypertension is defined as office systolic BP values $\geq 140 \mathrm{mmHg}$ and/or diastolic BP values $\geq 90 \mathrm{mmHg}$ according to 2018 ESC guidelines. We excluded those with hypertension in the current assessment. In the ESC guidelines, BP was defined as optimal blood pressure (OBP) < 120-80 mmHg; normal blood pressure (NBP) 120-129 and/or 80-84 mmHg; high normal blood pressure (HNBP) 130-139 and / or 85-89 mmHg according to office BP. The development of hypertension was defined by the evidence of systolic $\mathrm{BP} \geq 140 \mathrm{mmHg}$, and/or diastolic $\mathrm{BP} \geq 90 \mathrm{mmHg}$, and/or current antihypertensive therapy [11].

Weight was measured with light clothing and without shoes. A standard tape measure was used to determine the height and waist circumference, which was measured between the lowest rib and crista iliaca superior. Body mass index (BMI) was computed from values of weight/height squared and universally expressed in $\mathrm{kg} / \mathrm{m}^{2}$, resulting from mass in kilograms and height in meters.

\subsection{Laboratory Analysis and Statistics}

The whole blood samples were taken after overnight fasting and analyzed in a central laboratory. All laboratory determinations were analyzed with Beckman Coulter AU 2700 
auto-analyzer. Plasma 25-OH vitamin D was measured using the DiasorinLiason device by immunoassay method. Vitamin D levels were assessed according to the European Society of Endocrinology guideline. Glucose, creatinine, uric acid, Ca, P, albumin, GGT, LDH, ALP, AST, ALT, triglyceride, total cholesterol, HDL, and LDL levels were measured with Beckman Coulter AU 2700 auto analyzer with the photometric method. Intact PTH, insulin, fT3, fT4, and TSH levels were measured with Beckman Coulter Unicell DXI 800 device with immunoassay method. HsCRP level was measured with Coulter AU 680 device with the turbidimetric method. C-peptide levels were measured with the immunoassay method on the DiasorinLiason device. HbA1c levels were measured with the boronate affinitybased HPLC method on the Premiere Hb 9210 device. Insulin resistance was expressed as The Homeostasis Model Assessment of Insulin Resistance (HOMA-IR) and calculated as (fasting insulin $(\mathrm{mIU} / \mathrm{mL}) \times$ fasting glucose $(\mathrm{mg} / \mathrm{dL}) / 405)$.

Statistical analysis was performed by using Statistical Package for Social Sciences (SPSS) for Windows 16.0. Numerical values were expressed as main \pm standard deviation. Statistical associations were assessed using the Student $t$-test (parametric test) or Mann-Whitney $U$ test (non-parametric test). Logistic regression modeling was performed to identify a relationship between NOBP, 25-OH vitamin D, and HOMA-IR. A $p$-value $<0.05$ was statistically significant.

\section{Results}

A total of 491 patients were divided into two groups: NOBP and OBP. NOBP group included two subgroups: NBP and HNBP. A total of 289 people with NOBP, 101 men and 188 women, and 202 people with OBP, 54 of whom were male, and 148 were female, were analyzed.

\subsection{Associations of 25-OH Vitamin D and Normal-High Normal Blood Pressure}

A significantly lower mean vitamin $\mathrm{D}$ level of $27.8 \mathrm{nmol} / \mathrm{L}$ was detected in all patient populations. The mean levels of vitamin $\mathrm{D}$ were found to be $24.41 \pm 14.40 \mathrm{nmol} / \mathrm{L}$ in NOBP group and $32.53 \pm 31.50 \mathrm{nmol} / \mathrm{L}$ in OBP, and there was a significant statistical difference found $(p<0.001)$ (Table 1$)$. Figure 1 shows the distribution in the whole group according to the vitamin $\mathrm{D}$ level that is divided into groups with intervals of $5 \mathrm{nmol} / \mathrm{L}$. In the Figure 1, most of the patients had low vitamin D levels less than $<50 \mathrm{nmol} / \mathrm{L}$ (Figure 1).

Figure 2 shows the levels of vitamin D levels by dividing into $25 \mathrm{nmol} / \mathrm{L}$ quartiles into the study groups (NOBP and OBP). While the number of patients in the first quartile with the lowest vitamin D levels $(<25 \mathrm{nmol} / \mathrm{L})$ was higher, the number of patients in the fourth quartile with the higher vitamin D levels $(>75 \mathrm{nmol} / \mathrm{L})$ were lower in both study groups, and a serious deficiency of vitamin $\mathrm{D}<25 \mathrm{nmol} / \mathrm{L}$ were detected in $63.3 \%$ of the patients in the NOBP group (Figure 2).

Vitamin D and parathyroid hormone (PTH) levels between groups according to gender were shown in Figure 3. In both groups, vitamin D levels were higher in men compared to women. In contrast to vitamin D, PTH levels were higher in women compared to men (Figure 3).

The characteristics of participants according to 25-OH vitamin D and PTH levels and quartiles of BP levels were shown in Figure 4. Vitamin D average gradually decreases from the OBP group to HNBP group, and the difference between the groups was statistically significant $(p=0.008)$. The mean PTH gradually increases from the OBP group to HNBP group, but the difference between the groups was not statistically significant $(p=0.119)$ (Figure 4).

The mean systolic BP at baseline was $130.53 \pm 6.53$ and $107.65 \pm 6.61$, and diastolic $\mathrm{BP}$ was81.73 \pm 6.90 and $67.53 \pm 6.19$ in NOBP and OBP group, respectively, and there was a statistically significant difference between the two subgroups $(p<0.001)$ (Table 1$)$. 
Table 1. Comparison of anthropometric, blood pressure, and metabolic parameters between NOBP and OBP groups.

\begin{tabular}{|c|c|c|c|c|c|}
\hline & \multicolumn{2}{|c|}{ OBP $(n=202)$} & \multicolumn{2}{|c|}{ NOBP $(n=289)$} & \multirow[b]{2}{*}{$p$} \\
\hline & Mean & SS & Mean & SS & \\
\hline Age, years & 34.32 & 8.50 & 37.81 & 9.87 & $<0.001$ \\
\hline $\mathrm{SBP}, \mathrm{mm} \mathrm{Hg}$ & 107.65 & 6.61 & 130.53 & 6.53 & $<0.001$ \\
\hline $\mathrm{DBP}, \mathrm{mmHg}$ & 67.53 & 6.19 & 81.73 & 5.90 & $<0.001$ \\
\hline $\mathrm{MABP}, \mathrm{mmHg}$ & 80.90 & 5.74 & 98.00 & 5.53 & $<0.001$ \\
\hline Height, $\mathrm{cm}$ & 164.90 & 8.54 & 164.90 & 9.74 & $=0.998$ \\
\hline Weight, kg & 68.32 & 12.41 & 80.69 & 14.43 & $<0.001$ \\
\hline $\begin{array}{l}\text { Body mass index } \\
\mathrm{kg} / \mathrm{m}^{2}\end{array}$ & 25.10 & 4.50 & 29.73 & 5.14 & $<0.001$ \\
\hline $\begin{array}{c}\text { Waist } \\
\text { circumference, } \mathrm{cm}\end{array}$ & 83.82 & 10.26 & 95.57 & 11.06 & $<0.001$ \\
\hline $\begin{array}{c}\text { Fasted glucose, } \\
\mathrm{mg} / \mathrm{dL}\end{array}$ & 91.06 & 11.04 & 95.23 & 11.84 & $<0.001$ \\
\hline Creatinine, mg/dL & 0.67 & 0.15 & 0.66 & 0.14 & 0.871 \\
\hline $\mathrm{LDL}, \mathrm{mg} / \mathrm{dL}$ & 115.23 & 31.24 & 122.85 & 36.39 & $=0.017$ \\
\hline $\begin{array}{l}\text { Triglyceride, } \\
\text { mg/dL }\end{array}$ & 99.04 & 55.84 & 151.23 & 133.01 & $<0.001$ \\
\hline $\begin{array}{c}\text { Total cholesterol, } \\
\mathrm{mg} / \mathrm{dL}\end{array}$ & 184.73 & 37.15 & 197.59 & 44.39 & $<0.001$ \\
\hline Uric acid, mg/dL & 4.06 & 0.99 & 4.70 & 1.30 & $<0.001$ \\
\hline AST, U/L & 20.24 & 6.05 & 23.50 & 11.25 & $<0.001$ \\
\hline ALT, U/L & 18.77 & 10.39 & 26.45 & 22.83 & $<0.001$ \\
\hline GGT, U/L & 19.45 & 14.70 & 29.26 & 26.31 & $<0.001$ \\
\hline ALP, U/L & 72.92 & 24.28 & 81.48 & 25.24 & $<0.001$ \\
\hline Albumin, g/L & 4.36 & 0.31 & 4.32 & 0.29 & $=0.216$ \\
\hline Calcium, mg/dL & 9.57 & 0.50 & 9.60 & 0.48 & $=0.518$ \\
\hline Phosphor, mg/dL & 3.42 & 0.56 & 3.35 & 0.59 & $=0.258$ \\
\hline $\mathrm{PTH}, \mathrm{pg} / \mathrm{mL}$ & 49.60 & 23.98 & 58.08 & 26.33 & $<0.001$ \\
\hline $\begin{array}{l}\text { Vitamin D (25- } \\
\text { hydroxyvitamin } \\
\text { D), nmol/L }\end{array}$ & 32.53 & 31.50 & 24.41 & 14.40 & $<0.001$ \\
\hline $\mathrm{HbA1c}, \%$ & 5.33 & 0.46 & 5.52 & 0.39 & $<0.001$ \\
\hline $\begin{array}{c}\text { Fasted insulin, } \\
\mathrm{mU} / \mathrm{L}\end{array}$ & 6.96 & 7.13 & 9.58 & 7.61 & $<0.001$ \\
\hline HOMA-IR & 1.60 & 1.74 & 2.32 & 2.08 & $<0.001$ \\
\hline C peptide, ng/mL & 2.32 & 0.92 & 3.16 & 1.68 & $<0.001$ \\
\hline FT3, ng/dL & 3.23 & 0.38 & 3.22 & 0.40 & $=0.246$ \\
\hline FT4, ng/dL & 0.84 & 0.13 & 0.82 & 0.15 & $=0.330$ \\
\hline $\mathrm{TSH}, \mathrm{mIU} / \mathrm{L}$ & 1.81 & 1.31 & 1.95 & 1.32 & $=0.238$ \\
\hline $\mathrm{CRP}, \mathrm{mg} / \mathrm{L}$ & 0.96 & 2.17 & 2.08 & 4.05 & $<0.001$ \\
\hline
\end{tabular}

SBP, systolic blood pressure; DBP, diastolic blood pressure; MABP, mean arterial blood pressure; LDL, low-density lipoprotein; AST, aspartate aminotransferase; ALT, alanine aminotransferase; GGT, gamma-glutamyl transferase; ALP, alkaline phosphatase; HOMA-IR, Homeostatic Model Assessment for Insulin Resistance; FT3, free triiodothyronine; FT4, free thyroxine; TSH, thyroid-stimulating hormone; CRP, C-reactive protein; PTH, parathyroid hormone. 


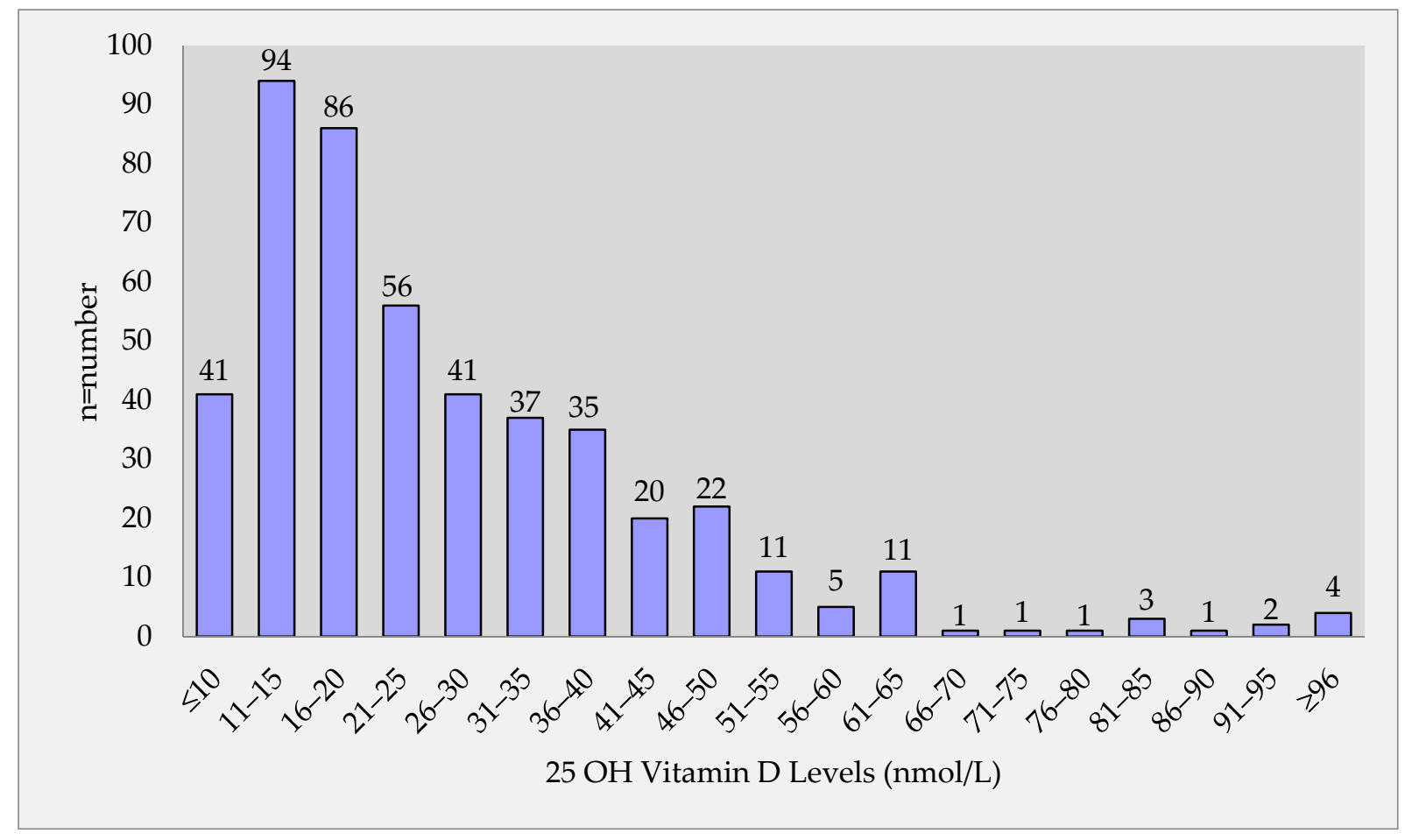

Figure 1. Distribution of patients according to vitamin D levels.

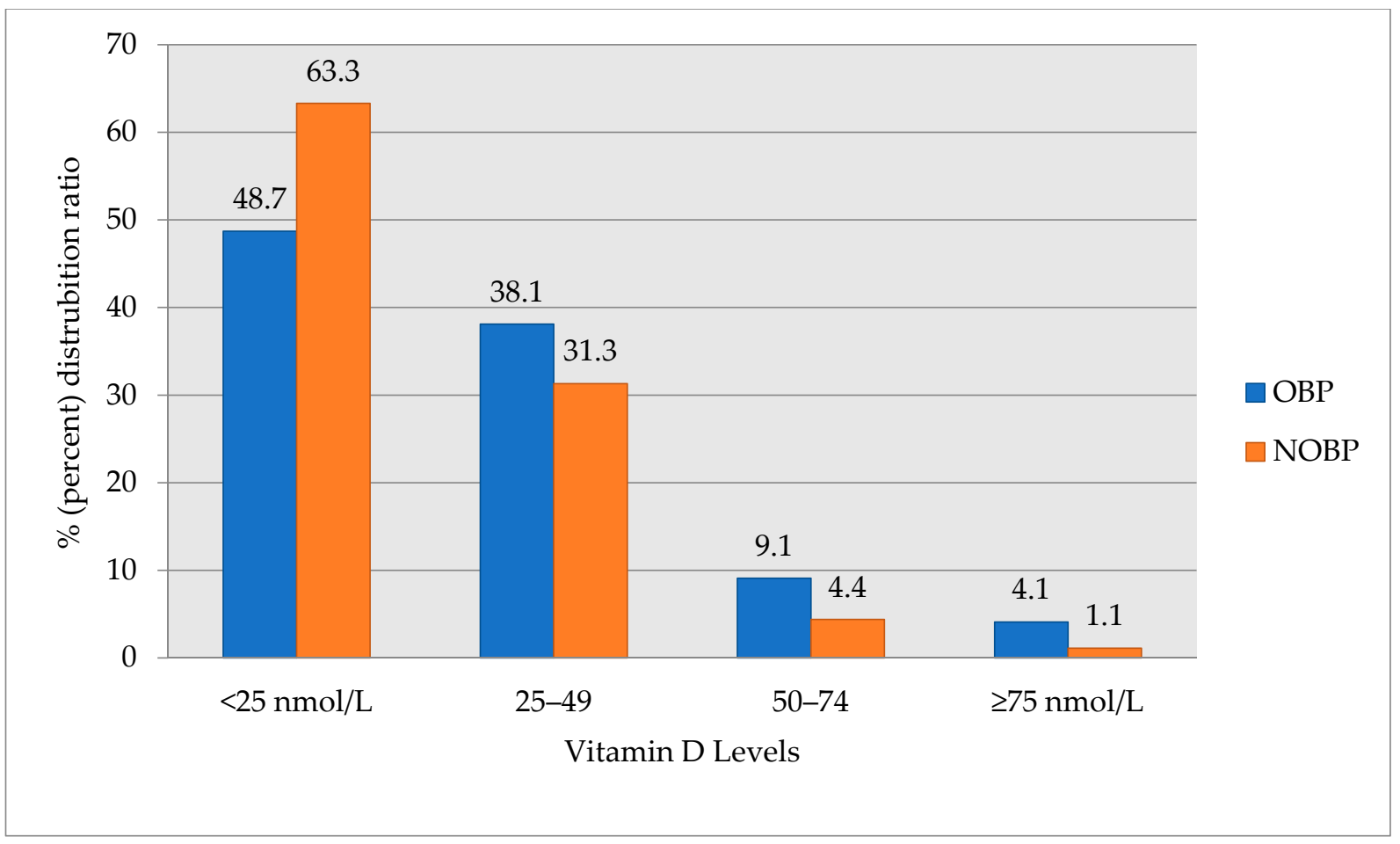

Figure 2. Distribution of vitamin D levels by groups. OBP, optimal blood pressure; NOBP, non-optimal blood pressure. 


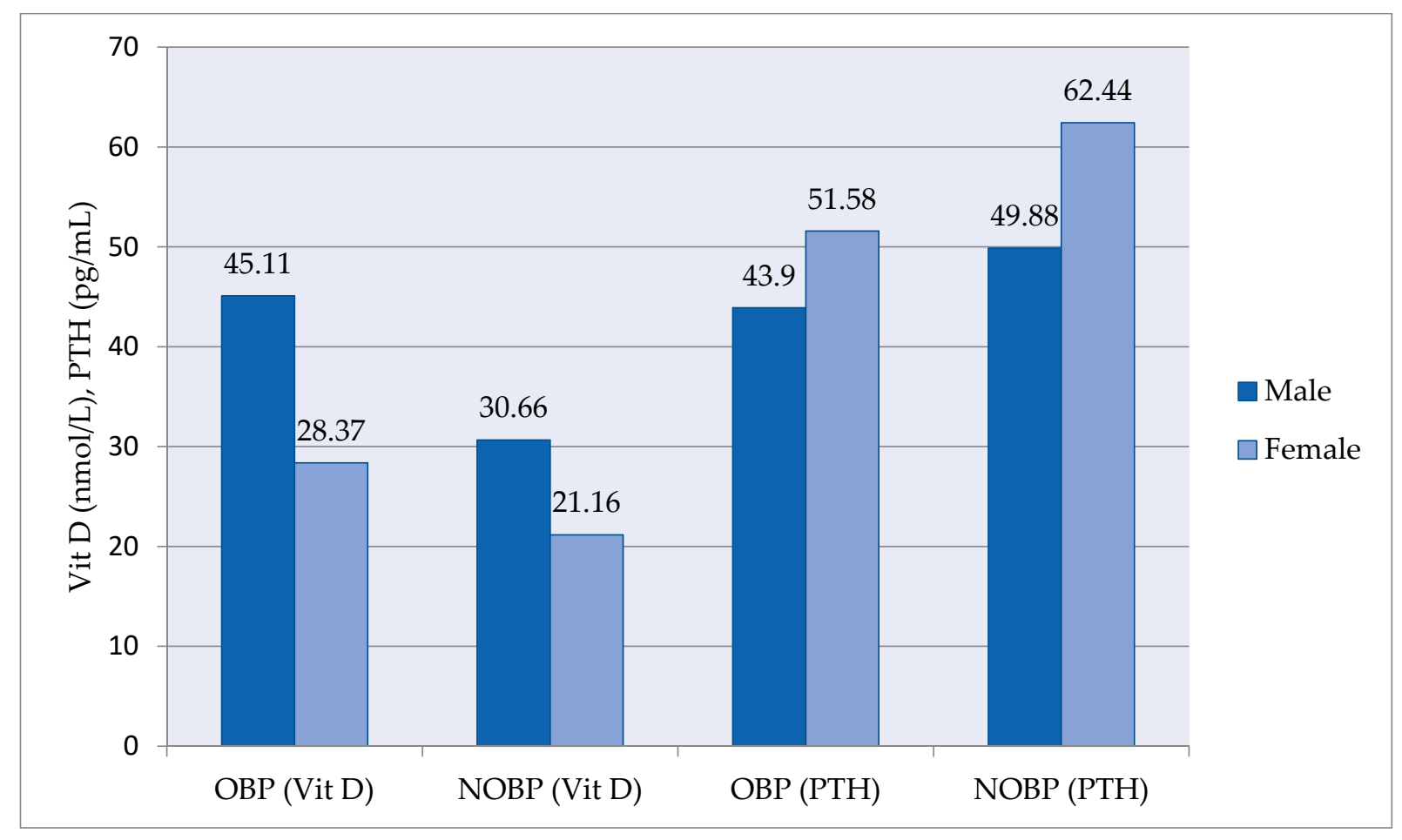

Figure 3. Comparison of vitamin D and PTH levels between groups (OBP and NOBP) by gender. OBP, optimal blood pressure; NOBP, non-optimal blood pressure; VitD, vitamin D; PTH, parathyroid hormone.

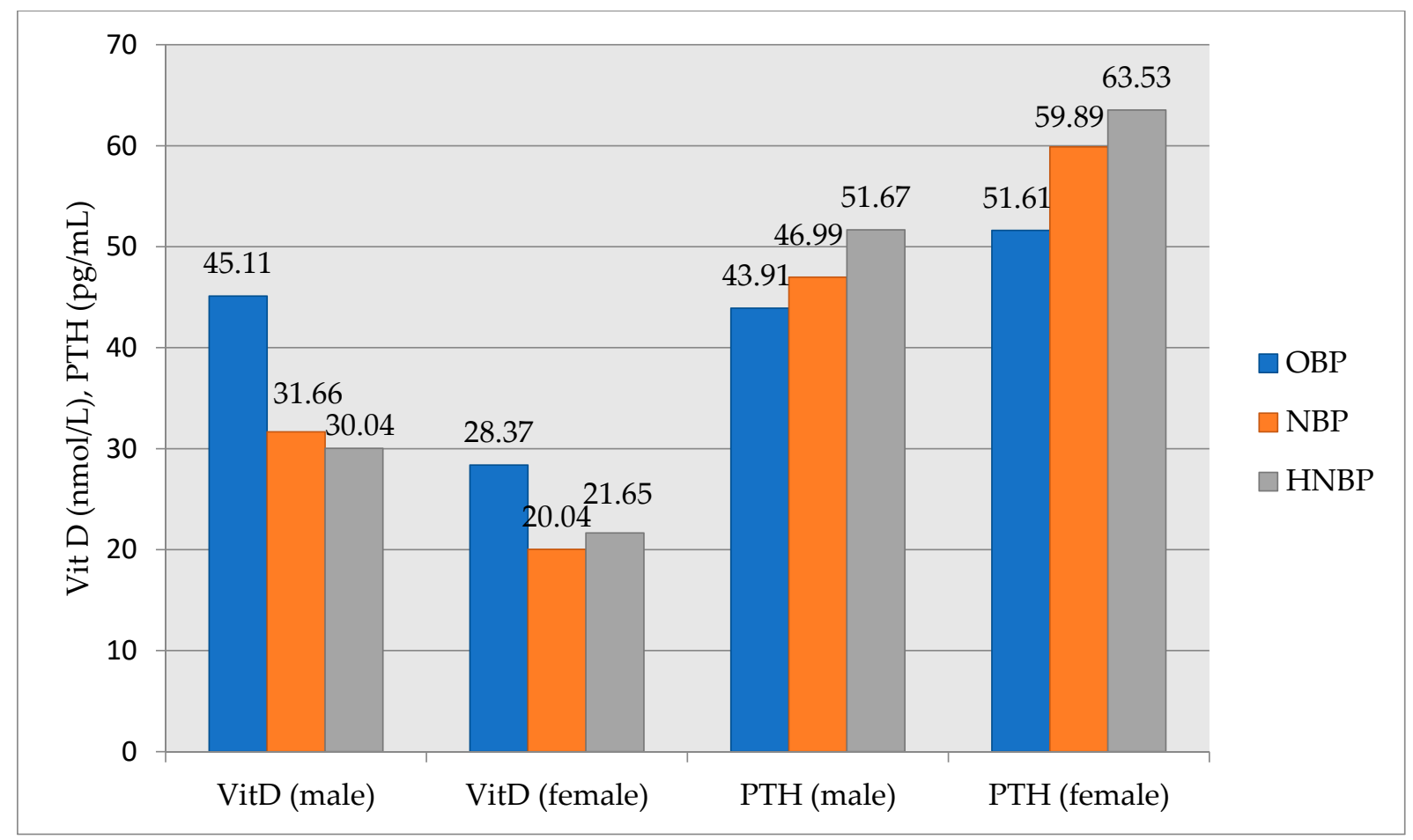

Figure 4. Comparison of vitamin D and PTH levels between subgroups (OBP, NBP, and HNBP) by gender. OBP, optimal blood pressure; NBP, normal blood pressure; HNBP, high-normal blood pressure; VitD, vitamin D; PTH, parathyroid hormone. 


\subsection{Associations of Other Metabolic Parameters and Non-Optimal Blood Pressure}

Table 1 shows the baseline characteristics of the study population. The average age is $34.32 \pm 8.50$ in OBP group and $37.81 \pm 9.87$ in NOBP group. Those in the NOBP group were more obese and had higher levels of total cholesterol, LDL, triglyceride, uric acid, AST, ALT, CRP, glucose, HbA1c, insulin, C-peptide, PTH, and HOMA-IR levels compared to OBP group $(p<0.001)$. Creatinine, calcium, phosphor, albumin, TSH, fT4, and fT3 levels did not differ between the two groups (Table 1 ).

In the logistic regression model, when the effect of the specified variables on NOBP are examined, the risk of developing NOBP increases with age $(p=0.047, \mathrm{OR}=1.024), 25-\mathrm{OH}$ vitamin D $(p=0.021, \mathrm{OR}=0.985)$, HOMA-IR $(p=0.047, \mathrm{OR}=1.229)$, and BMI $(p=0.000$, $\mathrm{OR}=1.199)($ Table 2$)$.

Table 2. The multivariate logistic regression model.

\begin{tabular}{ccccc}
\hline & $\boldsymbol{p}$ & OR & \multicolumn{2}{c}{ \%95 Confidence Interval } \\
\cline { 4 - 5 } & & & Low & High \\
\hline Age & 0.047 & 1.024 & 1.000 & 1.048 \\
\hline $\begin{array}{c}25(\mathrm{OH}) \text { vitamin } \\
\text { D }\end{array}$ & 0.021 & 0.985 & 0.972 & 0.998 \\
\hline HOMA-IR & 0.047 & 1.229 & 1.002 & 1.507 \\
\hline BMI & 0.000 & 1.199 & 1.133 & 1.270 \\
\hline Constant & 0.000 & 0.005 & &
\end{tabular}

HOMA-IR, Homeostatic Model Assessment for Insulin Resistance; BMI, body mass index.

\subsection{Development of Incident Hypertension and Other Chronic Diseases during Follow-Up}

Among 491 participants free of hypertension, 79 of them developed incident hypertension during an 8-year follow-up. There were 61 patients in the NOBP group and 18 patients in the OBP group (Table 3).

Table 3. Development of Hypertension, diabetes mellitus, and coronary artery disease at 8-year follow-up.

\begin{tabular}{cccc}
\hline & OBP $(\boldsymbol{n}=\mathbf{2 0 2})$ & NOBP $(\boldsymbol{n}=\mathbf{2 8 9})$ & $p$-Value \\
\hline Development of HT & 18 & 61 & $<0.001$ \\
\hline Development of DM & 15 & 37 & $=0.07$ \\
\hline Development of CAD & 11 & 21 & $=0.46$
\end{tabular}

OBP, optimal blood pressure; NOBP, non-optimal blood pressure; n, number; HT, hypertension; DM, diabetes mellitus; CAD, coronary artery disease.

The rate of developing hypertension was found to be significantly higher in the NOBP group with low vitamin D levels $(p<0.001)$ (Table 3$)$. The development of coronary artery disease in OBP was $5.9 \%$ and $7.6 \%$ in the NOBP group, and there was no statistical significance between the two groups $(p=0.46)$. The development of diabetes mellitus in the OBP was $8.0 \%$ and $13.5 \%$ in the NOBP group, and the NOBP group was found to be more susceptible to diabetes $(p=0.07)$ (Figure 5$)$. The odds ratio for the development of $\mathrm{HT}$ in NOBP was 2.67. 


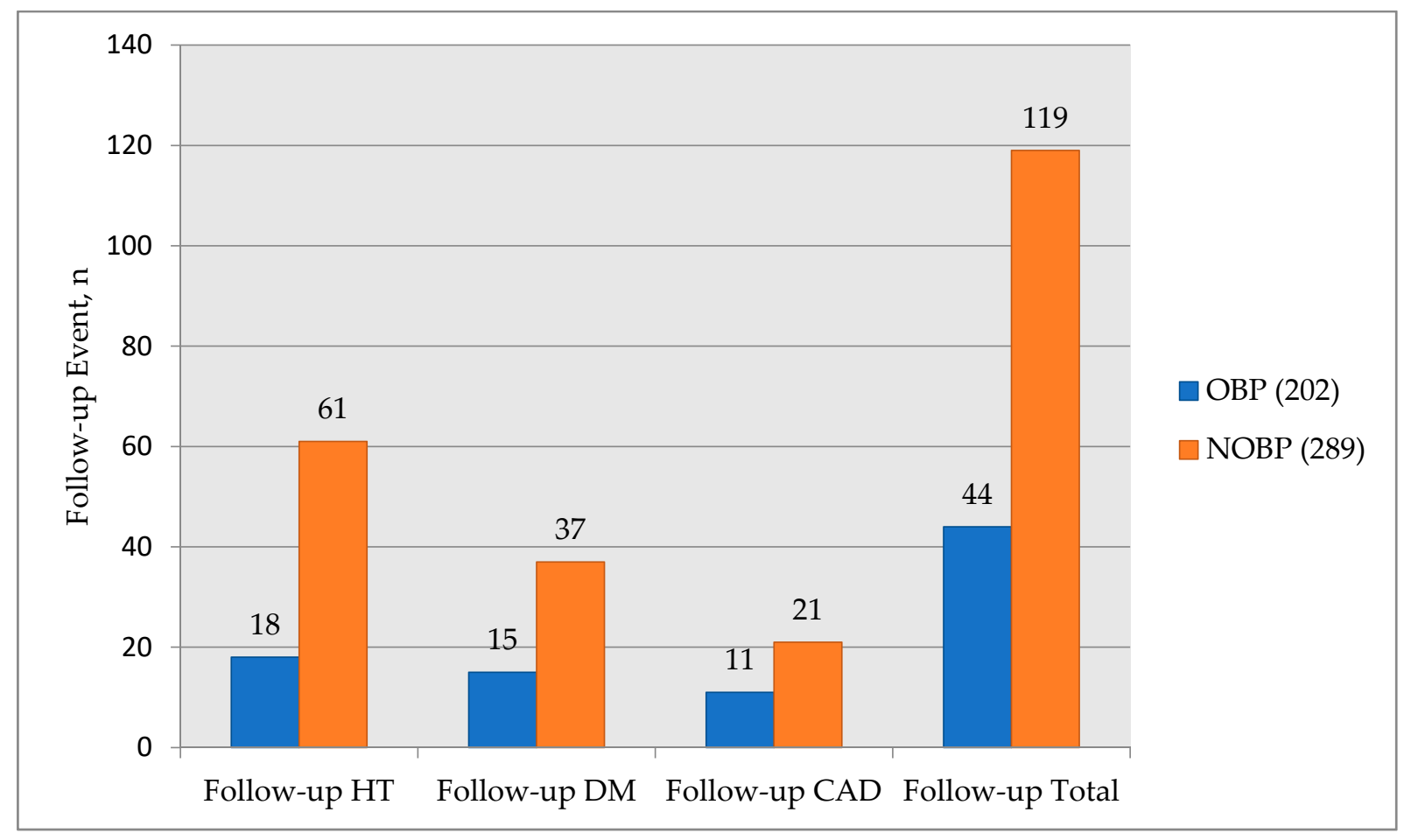

Figure 5. Comparison of events at 8-year follow-up. OBP, optimal blood pressure; NOBP, non-optimal blood pressure; $n$, number; HT, hypertension; DM, diabetes mellitus; CAD, coronary artery disease.

\section{Discussion}

The association between vitamin D levels and BP was previously reported in several numbers of studies, and lower 25-OH vitamin D levels were associated with higher blood pressures and higher prevalence of hypertension [12-15]. However, there is no consensus on this issue, and there are studies that do not support this association. Unlike other studies, our study specifically examined the relationship between vitamin $\mathrm{D}$ and normal-high normal pressure in disease-free adults and examined the development of hypertension and other events in long-term follow-up. There was a strong negative association between vitamin D and BP levels in our study population. Like our study, Jorde et al. revealed a strong relationship between hypertension and vitamin D. However, there was no association between vitamin $\mathrm{D}$ and future hypertension development different from our study [16]. In the study by Sabanayagam et al., low vitamin D levels were found to be associated with pre-hypertension in U.S. adults [17]. Although Turkey has high sunlight exposure, vitamin $D$ deficiency is still seen at high rates, and baseline vitamin D levels were very low in the study population due to the ethnic structure of the Turkish society. In the meta-analysis, although $63 \%$ of vitamin D deficiency was detected in the Turkish population, this rate was found to be higher in our study group [18]. The reason for this can be that they live in a metropolis like Istanbul, and as a result, they may spend long periods in closed areas. This percent is found in approximately $40 \%$ of the European population and is lower than in the Turkish population [19].

It has been shown that up-regulation of the renin-angiotensin-aldosterone system (RAAS) is an important risk factor for the development of hypertension [20-22]. Vitamin $\mathrm{D}$ has been shown to affect the RAAS in various ways by binding to vitamin D receptors in different human and animal studies $[23,24]$. Forman et al. showed that lower 25$\mathrm{OH}$ vitamin $\mathrm{D}$ levels were associated with higher circulating angiotensin 2 levels and blunted renal plasma flow responses to infused angiotensin II in renal plasma flow in vitamin D insufficient group compared with sufficient vitamin D levels [23]. This increase in angiotensin 2 levels leads to hypertension, cardiac hypertrophy, and increased water intake. The suppression of renin expression by vitamin $\mathrm{D}$ is different from its role in 
calcium metabolism. This is associated with the sensing mechanism of the volume with salt and angiotensin 2 feedback regulations [25]. Li et al. found that renin expression was increased in mice whose vitamin D receptor was removed. As a result of increased renin level, angiotensin II increased and lead to the development of hypertension and cardiac hypertrophy in vitamin D receptor null mice [22]. They also showed that $25-\mathrm{OH}$ vitamin D directly inhibits renin gene transcription [26]. Vaidya et al. found that the polymorphism in the Fok1 vitamin D receptor gene caused an increase in plasma renin level and the development of hypertension. The results showed that vitamin $\mathrm{D}$ is a potential regulator of renin activity in humans [27]. These results showed that vitamin D deficiency increased RAAS activation.

Secondarily, other than the RAAS, low vitamin D levels are associated with increased insulin resistance, which plays a role in the pathogenesis of hypertension [28].

Third, the study shows that vitamin D inhibits vascular muscle cell proliferation; as a result, low levels of vitamin D cause hypertension development as a result of vascular muscle cell proliferation [29].

Vitamin D replacement has been found to have an antihypertensive effect in the reported studies [30]. On the contrary, in some studies, the antihypertensive effect of vitamin D replacement could not be demonstrated, and it has not been revealed at what rate the development of hypertension could be prevented or delayed if vitamin D replacement was given to this pre-hypertensive group. In the study, vitamin D3 treatment in obese hypertensive's regulates angiotensin 2 activity in tissues and increases angiotensin 2 sensitivity in tissues similar to angiotensin converting enzyme inhibitors [31]. The effect of vitamin D replacement on pre-hypertension and stage 1 hypertension was not shown in the DAYLIGHT randomized, prospective study conducted with 591 patients [32]. The effectiveness of vitamin $\mathrm{D}$ for the treatment of hypertension can be due to characteristics of the study population, different sample sizes, short duration of treatment, low-dose usage of vitamin D, and lower follow-up period. Further studies with a bigger study population must be done.

In addition to its well-known role in calcium metabolism, high PTH levels have been shown to increase many cardiovascular risk factors along with hypertension [33-36]. Both secondary hyperparathyroidism and hypocalcemia due to vitamin D deficiency and primary hyperparathyroidism independent from vitamin D levels are associated with cardiovascular pathology. In a meta-analysis, circulating PTH levels were associated with a higher risk of arterial hypertension. In an American sample with 3002 participants, higher serum PTH levels were significantly associated with a greater risk of incident hypertension [37]. We assessed simultaneously both vitamin D and PTH, and our findings showed that higher PTH levels were significantly associated with higher BP levels. BP increasing the effect of PTH except in regulating the $25-\mathrm{OH}$ vitamin D level can be due to increasing renin release from the kidney, causing endothelial dysfunction, increasing arterial stiffness, and activating the sympathetic system [38-40].

Vitamin deficiency has also been shown to be a risk factor for metabolic syndrome. An inverse relationship was found between vitamin D levels and increased BP, high triglycerides, low HDL, increased waist circumference, and elevated fasting glucose, which are components of metabolic syndrome [41]. HNBP is also one of the components of metabolic syndrome, and a strong inverse relationship was found with vitamin D in our study with other metabolic syndrome components.

Classically, serum $25 \mathrm{OH}$ form of vitamin $\mathrm{D}$ is measured to show the level of vitamin D. We measured the 25-OH vitamin D with the immunoassay method. Slominski et al. detected CYP11A1-derived secosteroids in the human epidermis and serum as well as the porcine adrenal gland, which acted as hormones in vivo [42]. They detected these active metabolites of vitamin D by using liquid chromatography-tandem mass spectrometry [43]. They also revealed that CYP11A1 plays an important role in the skin's protective barrier and immune functions by playing a role in local steroidogenesis and vitamin D metabolism in the skin [44]. From these findings, although secosteroids have a role in the cellular effects 
of vitamin D, circulating 25-hydroxycholecalciferol is considered a clinical indicator of vitamin D status [45].

As expected, we have investigated that the development of hypertension was extremely higher in the NOBP subjects compared with the OBP subjects in an 8-year followup. As opposed to hypertension, coronary artery disease development was not found high in the NOBP group. The development of diabetes tended to be higher in the NOBP group compared to the OBP group.

The strengths of our study are that the significance of the results is very high. In addition, by using vitamin D together with PTH and other laboratory parameters, the independent prognostic value of these values was determined. In addition, our study has a long follow-up period of eight years. Numerous studies and meta-analyses have suggested that vitamin D deficiency has a negative association with hypertension; however, this effect has been seldom studied in the Turkish population.

The limitations of our study are a low number of patients, and they are from a single center. The other limitation is population-based nature. The seasonal variation of vitamin D may also affect its levels. Although Liquid Chromatography-tandem Mass Spectrometry method is the gold standard method for vitamin D measurement now, we used the immunoassay method. Another possible limitation is the measurement of vitamin $\mathrm{D}$ and hypertension at a single fixed time. Although $1.25-\mathrm{OH}$ vitamin $\mathrm{D}$ is the active metabolite, only $25-\mathrm{OH}$ vitamin D could be measured in this study. Dietary habits or the use of salt could not be standardized for the development of hypertension.

\section{Conclusions}

In conclusion, our study suggests that serum 25-OH vitamin D levels are independently associated with normal to high normal blood pressure and risk of incident hypertension in a middle-aged Turkish population in the prospective study. Along with the negative correlation between vitamin $\mathrm{D}$ level and blood pressure in non-hypertensive individuals, the development of hypertension in patients with high-normal and normal blood pressure in an 8-year follow-up is a striking result. Further population studies with a large number of patients are needed to evaluate the role of serum $25-\mathrm{OH}$ vitamin $\mathrm{D}$ supplementation and/or level in preventing or delaying the development of hypertension in pre-hypertensive patients. Since vitamin D values in our study group and Turkish society were found to be very low, a community nutrition program should be developed to increase its level.

Author Contributions: Conceptualization, Y.K. and F.Ö.-K.; data curation, Y.K.; formal analysis, E.A. and G.C.; funding acquisition, Y.K.; investigation, Y.K.; methodology, S.A. and E.A.; project administration, F.Ö.-K.; resources, F.Ö.-K.; software, Y.K.; supervision, Y.K.; validation, F.Ö.-K.; visualization, S.A. and E.A.; writing—original draft, Y.K. and F.Ö.-K.; writing—review andediting, Y.K. and F.Ö.-K. All authors have read and agreed to the published version of the manuscript.

Funding: This research received no external funding.

Institutional Review Board Statement: The study was conducted according to the guidelines of the Declaration of Helsinki, and Haseki Training and Research Hospital Ethics Committee approved the study with the approval no: 60 and the date 5 March 2014.

Informed Consent Statement: Patient consent was waived due to as information obtained from hospital records is used.

Data Availability Statement: The datasets generated for this study are available on request to the corresponding author.

Conflicts of Interest: The authors declare no conflict of interest. 


\section{References}

1. Mithal, A.; Wahl, D.A.; Bonjour, J.P.; Burckhardt, P.; Dawson-Hughes, B.; Eisman, J.A.; El-Hajj Fuleihan, G.; Josse, R.G.; Lips, P.; Morales-Torres, J. IOF Committee of Scientific Advisors (CSA) Nutrition Working Group. Global vitamin D status and determinants of hypovitaminosis D. Osteoporos Int. 2009, 20, 1807-1820. [CrossRef]

2. Hekimsoy, Z.; Dinç, G.; Kafesçiler, S.; Onur, E.; Güvenç, Y.; Pala, T.; Güçlü, F.; Ozmen, B. Vitamin D status among adults in the Aegean region of Turkey. BMC Public Health 2010, 10, 782-789. [CrossRef]

3. Cigerli, O.; Parildar, H.; Unal, A.D.; Tarcin, O.; Erdal, R.; GuvenerDemirag, N. Vitamin D deficiency is a problem for adult out-patients? A university hospital sample in Istanbul, Turkey. Public Health Nutr. 2013, 16, 1306-1313. [CrossRef] [PubMed]

4. Norman, P.E.; Powell, J.T. Vitamin D and cardiovascular disease. Circ. Res. 2014, 114, 379-393. [CrossRef] [PubMed]

5. Sassi, F.; Tamone, C.; D'Amelio, P. Vitamin D: Nutrient, Hormone, and Immunomodulator. Nutrients 2018, 10, 1656. [CrossRef] [PubMed]

6. Costantini, E.; Sinjari, B.; Piscopo, F.; Porreca, A.; Reale, M.; Caputi, S.; Murmura, G. Evaluation of Salivary Cytokines and Vitamin D Levels in Periodontopathic Patients. Int. J. Mol. Sci. 2020, 21, 2669. [CrossRef]

7. Mills, K.T.; Bundy, J.D.; Kelly, T.N.; Reed, J.E.; Kearney, P.M.; Reynolds, K.; Chen, J.; He, J. Global Disparities of Hypertension Prevalence and Control: A Systematic Analysis of Population-Based Studies From 90 Countries. Circulation 2016, 134, 441-450. [CrossRef]

8. Barbarawi, M.; Kheiri, B.; Zayed, Y.; Barbarawi, O.; Dhillon, H.; Swaid, B.; Yelangi, A.; Sundus, S.; Bachuwa, G.; Alkotob, M.L.; et al. Vitamin D Supplementation and Cardiovascular Disease Risks in More Than 83,000 Individuals in 21 Randomized Clinical Trials: A Meta-analysis. JAMA Cardiol. 2019, 4, 765-776. [CrossRef]

9. Vaidya, A.; Williams, J.S. The relationship between vitamin D and the renin-angiotensin system in the pathophysiology of hypertension, kidney disease, and diabetes. Metabolism 2012, 61, 450-458. [CrossRef]

10. Egan, B.M.; Stevens-Fabry, S. Prehypertension-prevalence, health risks, and management strategies. Nat. Rev. Cardiol. 2015, 12, 289-300. [CrossRef]

11. Williams, B.; Mancia, G.; Spiering, W.; AgabitiRosei, E.; Azizi, M.; Burnier, M.; Clement, D.L.; Coca, A.; de Simone, G.; Dominiczak, A.; et al. 2018 ESC/ESH Guidelines for the management of arterial hypertension: The Task Force for the management of arterial hypertension of the European Society of Cardiology and the European Society of Hypertension: The Task Force for the management of arterial hypertension of the European Society of Cardiology and the European Society of Hypertension. J. Hypertens. 2018, 36, 1953-2041. [PubMed]

12. Vimaleswaran, K.S.; Cavadino, A.; Berry, D.J.; LifeLines Cohort Study Investigators; Jorde, R.; Dieffenbach, A.K.; Lu, C.; Alves, A.C.; Heerspink, H.J.; Tikkanen, E.; et al. Association of vitamin D status with arterial blood pressure and hypertension risk: A mendelian randomisation study. Lancet Diabetes Endocrinol. 2014, 2, 719-729. [CrossRef]

13. Kim, M.K.; Il Kang, M.; Won Oh, K.; Kwon, H.S.; Lee, J.H.; Lee, W.C.; Yoon, K.H.; Son, H.Y. The association of serum vitamin D level with presence of metabolic syndrome and hypertension in middle-aged Korean subjects. Clin. Endocrinol. 2010, 73, 330-338. [CrossRef] [PubMed]

14. Zhao, G.; Ford, E.S.; Li, C.; Kris-Etherton, P.M.; Etherton, T.D.; Balluz, L.S. Independent associations of serum concentrations of 25-hydroxyvitamin D and parathyroid hormone with blood pressure among US adults. J. Hypertens. 2010, 28, 1821-1828. [CrossRef] [PubMed]

15. Kunutsor, S.K.; Apekey, T.A.; Steur, M. Vitamin D and risk of future hypertension: Meta-analysis of 283,537 participants. Eur. J. Epidemiol. 2013, 28, 205-221. [CrossRef] [PubMed]

16. Jorde, R.; Figenschau, Y.; Emaus, N.; Hutchinson, M.; Grimnes, G. Serum 25-hydroxyvitamin D levels are strongly related to systolic blood pressure but do not predict future hypertension. Hypertension 2010, 55, 792-798. [CrossRef]

17. Sabanayagam, C.; Shankar, A.; Somasundaram, S. Serum vitamin D level and prehypertension among subjects free of hypertension. Kidney Blood Press. Res. 2012, 35, 106-113. [CrossRef]

18. Alpdemir, M.; Alpdemir, M.F. Meta Analysis Vitamin D deficiency status in Turkey: A meta-analysis. Int. J. Med. Biochem. 2019, 2, 118-131.

19. Cashman, K.D.; Dowling, K.G.; Škrabáková, Z.; Gonzalez-Gross, M.; Valtueña, J.; De Henauw, S.; Moreno, L.; Damsgaard, C.T.; Michaelsen, K.F.; Mølgaard, C.; et al. Vitamin D deficiency in Europe: Pandemic? Am. J. Clin. Nutr. 2016, 103, 1033-1044. [CrossRef]

20. Becher, U.M.; Endtmann, C.; Tiyerili, V.; Nickenig, G.; Werner, N. Endothelial damage and regeneration: The role of the renin-angiotensin-aldosterone system. Curr. Hypertens. Rep. 2011, 13, 86-92. [CrossRef]

21. Briet, M.; Schiffrin, E.L. Vascular actions of aldosterone. J. Vasc. Res. 2013, 50, 89-99. [CrossRef]

22. Li, Y.C.; Kong, J.; Wei, M.; Chen, Z.F.; Liu, S.Q.; Cao, L.P. 1,25-Dihydroxyvitamin D(3) is a negative endocrine regulator of the renin-angiotensin system. J. Clin. Investig. 2002, 110, 229-238. [CrossRef] [PubMed]

23. Forman, J.P.; Williams, J.S.; Fisher, N.D. Plasma 25-hydroxyvitamin D and regulation of the renin-angiotensin system in humans. Hypertension 2010, 55, 1283-1288. [CrossRef] [PubMed]

24. Santoro, D.; Caccamo, D.; Lucisano, S.; Buemi, M.; Sebekova, K.; Teta, D.; De Nicola, L. Interplay of vitamin D, erythropoiesis, and the renin-angiotensin system. Biomed. Res. Int. 2015, 2015, 145828. [CrossRef] [PubMed]

25. Ullah, M.I.; Uwaifo, G.I.; Nicholas, W.C.; Koch, C.A. Does vitamin d deficiency cause hypertension? Current evidence from clinical studies and potential mechanisms. Int. J. Endocrinol. 2010, 2010, 579640. [CrossRef] 
26. Li, Y.C.; Qiao, G.; Uskokovic, M.; Xiang, W.; Zheng, W.; Kong, J. Vitamin D: A negative endocrine regulator of the renin-angiotensin system and blood pressure. J. Steroid Biochem. Mol. Biol. 2004, 89, 387-392. [CrossRef]

27. Vaidya, A.; Sun, B.; Forman, J.P.; Hopkins, P.N.; Brown, N.J.; Kolatkar, N.S.; Williams, G.H.; Williams, J.S. The Fok1 vitamin D receptor gene polymorphism is associated with plasma renin activity in Caucasians. Clin. Endocrinol. 2011, 74, 783-790. [CrossRef]

28. Szymczak-Pajor, I.; Śliwińska, A. Analysis of Association between Vitamin D Deficiency and Insulin Resistance. Nutrients 2019, 11, 794. [CrossRef] [PubMed]

29. Carthy, E.P.; Yamashita, W.; Hsu, A.; Ooi, B.S. 1,25-Dihydroxyvitamin D3 and rat vascular smooth muscle cell growth. Hypertension 1989, 13, 954-959. [CrossRef]

30. Chen, S.; Sun, Y.; Agrawal, D.K. Vitamin D deficiency and essential hypertension. J. Am. Soc. Hypertens. 2015, 9, 885-901. [CrossRef]

31. Vaidya, A.; Sun, B.; Larson, C.; Forman, J.P.; Williams, J.S. Vitamin D3 therapy corrects the tissue sensitivity to angiotensin ii akin to the action of a converting enzyme inhibitor in obese hypertensives: An interventional study. J. Clin. Endocrinol. Metab. 2012, 97, 2456-2465. [CrossRef] [PubMed]

32. Arora, P.; Song, Y.; Dusek, J.; Plotnikoff, G.; Sabatine, M.S.; Cheng, S.; Valcour, A.; Swales, H.; Taylor, B.; Carney, E.; et al. Vitamin D therapy in individuals with prehypertension or hypertension: The DAYLIGHT trial. Circulation 2015, 131, 254-262. [CrossRef] [PubMed]

33. Anderson, J.L.; Vanwoerkom, R.C.; Horne, B.D.; Bair, T.L.; May, H.T.; Lappé, D.L.; Muhlestein, J.B. Parathyroid hormone, vitamin D, renal dysfunction, and cardiovascular disease: Dependent or independent risk factors? Am. Heart J. 2011, 162, 331-339. [CrossRef] [PubMed]

34. Bosworth, C.; Sachs, M.C.; Duprez, D.; Hoofnagle, A.N.; Ix, J.H.; Jacobs, D.R.; Peralta, C.A.; Siscovick, D.S.; Kestenbaum, B.; de Boer, I.H. Parathyroid hormone and arterial dysfunction in the multi-ethnic study of atherosclerosis. Clin. Endocrinol. 2013, 79, 429-436. [CrossRef]

35. Luigi, P.; Chiara, F.M.; Laura, Z.; Cristiano, M.; Giuseppina, C.; Luciano, C.; Giuseppe, P.; Sabrina, C.; Susanna, S.; Antonio, C.; et al. Arterial Hypertension, Metabolic Syndrome and Subclinical Cardiovascular Organ Damage in Patients with Asymptomatic Primary Hyperparathyroidism before and after Parathyroidectomy: Preliminary Results. Int. J. Endocrinol. 2012, 2012 , 408295. [CrossRef]

36. Zhang, Y.; Zhang, D.Z. Circulating parathyroid hormone and risk of hypertension: A meta-analysis. Clin. Chim. Acta 2018, 482, 40-45. [CrossRef]

37. Van Ballegooijen, A.J.; Kestenbaum, B.; Sachs, M.C.; de Boer, I.H.; Siscovick, D.S.; Hoofnagle, A.N.; Ix, J.H.; Visser, M.; Brouwer, I.A. Association of 25-hydroxyvitamin D and parathyroid hormone with incident hypertension: MESA (Multi-Ethnic Study of Atherosclerosis). J. Am. Coll. Cardiol. 2014, 63, 1214-1222. [CrossRef]

38. Tomaschitz, A.; Pilz, S.; Ritz, E.; Grammer, T.; Drechsler, C.; Boehm, B.O.; März, W. Independent association between 1,25dihydroxyvitamin D, 25-hydroxyvitamin D and the renin-angiotensin system: The Ludwigshafen Risk and Cardiovascular Health (LURIC) study. Clin. Chim. Acta 2010, 411, 1354-1360. [CrossRef]

39. Pirro, M.; Manfredelli, M.R.; Helou, R.S.; Scarponi, A.M.; Schillaci, G.; Bagaglia, F.; Melis, F.; Mannarino, E. Association of parathyroid hormone and 25-OH-vitamin D levels with arterial stiffness in postmenopausal women with vitamin D insufficiency. J. Atheroscler. Thromb. 2012, 19, 924-931. [CrossRef]

40. Kim, D.; Kim, J. Association of Serum 25-Hydroxyvitamin D and Parathyroid Hormone with Hypertension in Middle-Aged and Older Korean Adults. Am. J. Hypertens. 2016, 29, 96-103. [CrossRef]

41. Melguizo-Rodríguez, L.; Costela-Ruiz, V.J.; García-Recio, E.; De Luna-Bertos, E.; Ruiz, C.; Illescas-Montes, R. Role of Vitamin D in the Metabolic Syndrome. Nutrients 2021, 13, 830. [CrossRef]

42. Slominski, A.T.; Kim, T.K.; Li, W.; Postlethwaite, A.; Tieu, E.W.; Tang, E.K.Y.; Tuckey, R.C. Detection of novel CYP11A1-derived secosteroids in the human epidermis and serum and pig adrenal gland. Sci. Rep. 2015, 8, 14875. [CrossRef] [PubMed]

43. Jenkinson, C.; Desai, R.; Slominski, A.T.; Tuckey, R.C.; Hewison, M.; Handelsman, D.J. Simultaneous measurement of 13 circulating vitamin D3 and D2 mono and dihydroxy metabolites using liquid chromatography mass spectrometry. Clin. Chem. Lab. Med. 2021, 59, 1642-1652. [CrossRef] [PubMed]

44. Slominski, R.M.; Raman, C.; Elmets, C.; Jetten, A.M.; Slominski, A.T.; Tuckey, R.C. The significance of CYP11A1 expression in skin physiology and pathology. Mol. Cell. Endocrinol. 2021, 530, 111238. [CrossRef]

45. Alvarez, J.A.; Ashraf, A. Role of vitamin d in insulin secretion and insulin sensitivity for glucose homeostasis. Int. J. Endocrinol. 2010, 2010, 351385. [CrossRef] [PubMed] 